\title{
Upregulation of Substance P in Low-Threshold Myelinated Afferents Is Not Required for Tactile Allodynia in the Chronic Constriction Injury and Spinal Nerve Ligation Models
}

\author{
David I. Hughes, Dugald T. Scott, John S. Riddell, and Andrew J. Todd \\ Spinal Cord Group, Institute of Biomedical and Life Sciences, University of Glasgow, Glasgow G12 8QQ, United Kingdom
}

It has been proposed that substance $\mathrm{P}$ and calcitonin gene-related peptide (CGRP) are upregulated in low-threshold myelinated primary afferents after certain types of nerve injury, and that release of substance $P$ from these afferents contributes to the resulting tactile allodynia. To test this hypothesis, we looked for neuropeptides in $\mathrm{A} \beta$ primary afferent terminals in the ipsilateral gracile nucleus and spinal dorsal horn in three nerve injury models: sciatic nerve transection (SNT), spinal nerve ligation (SNL), and chronic constriction injury (CCI). We also looked for evidence of neurokinin 1 (NK1) receptor internalization in the dorsal horn after electrical stimulation of $\mathrm{A} \beta$ afferents. We found no evidence of either substance P or CGRP expression in injured A $\beta$ terminals in the spinal cord in any of the models. Although substance $P$ was not detected in terminals of injured afferents in the gracile nucleus, CGRP was expressed in between 32 and $68 \%$ of these terminals, with a significantly higher proportion in the SNL and CCI models, compared with SNT. In addition, we did not detect any A $\beta$-evoked NK1 receptor internalization in neurons from laminas I, III, or IV of the dorsal horn in the CCI or SNL models. These results do not support the proposal that substance $\mathrm{P}$ is present at significant levels in the terminals of injured $\mathrm{A} \beta$ primary afferents in neuropathic models. They also suggest that any release of substance P from injured A $\beta$ afferents is unlikely to activate NK1 receptors in the dorsal horn or contribute to neuropathic pain.

Key words: peripheral nerve injury; CGRP; NK1 receptor; neuropathic pain; hyperalgesia; NPY

\section{Introduction}

Large myelinated $(A \beta)$ cutaneous primary afferent axons terminate in the spinal dorsal horn, occupying an area that extends from the inner part of lamina II (IIi) to lamina V, and some also send branches to the gracile or cuneate nuclei (Brown, 1981; Willis and Coggeshall, 2004; Todd and Koerber, 2005). Most of these axons transmit information from low-threshold mechanoreceptors, and stimulation of $\mathrm{A} \beta$ afferents generally gives rise to nonpainful sensations (Torebjörk et al., 1987). However, the tactile allodynia that often develops after peripheral nerve injuries is at least partly mediated by A $\beta$ afferents (Campbell et al., 1988; Gracely et al., 1992; Ochoa and Yarnitsky, 1993).

Nerve injury results in substantial changes in neuropeptide expression by unmyelinated (C) fibers [for example, downregulation of substance $P$ and calcitonin gene-related peptide (CGRP) and upregulation of galanin] (Hökfelt et al., 1994). Although low-threshold myelinated afferents do not normally synthesize neuropeptides, it is well established that they can upregulate neuropeptide Y (NPY) after peripheral axotomy (Wakisaka et al., 1991, 1992; Zhang et al., 1993).

Received Dec. 14, 2006; revised Jan. 19, 2007; accepted Jan. 20, 2007

This work was supported by the Wellcome Trust. We thank R. Kerr, C. Watt, M. McGill, and B. Finney for expert technical assistance, and Prof. D. J. Maxwell for advice.

Correspondence should be addressed to Dr. David I. Hughes, Spinal Cord Group, West Medical Building, University of Glasgow, University Avenue, Glasgow G12 8QQ, UK. E-mail: d.hughes@bio.gla.ac.uk.

DOI:10.1523/JNEUROSCI.5401-06.2007

Copyright $\odot 2007$ Society for Neuroscience $\quad$ 0270-6474/07/272035-10\$15.00/0
It has been proposed that nerve injury can also lead to upregulation of substance $\mathrm{P}$ in $\mathrm{A} \beta$ afferents. Noguchi et al. (1995) reported that, after spinal nerve transection, PPT (preprotachykinin) mRNA, which codes for substance $\mathrm{P}$, was present in large dorsal root ganglion neurons, while substance $\mathrm{P}$ was detected in large myelinated peripheral nerve fibers. They also found that sciatic nerve transection (SNT) caused an increase in the level of substance $\mathrm{P}$ in the gracile nucleus, although not in laminas III-IV of the dorsal horn. Allen et al. (1999) failed to detect internalization of the neurokinin 1 (NK1) receptor (a measure of substance $\mathrm{P}$ release) after stimulating $\mathrm{A} \beta$ fibers in chronically transected sciatic nerves, and Malcangio et al. (2000) did not observe substance $P$ release in spinal cord slices after stimulation of $A \beta$ fibers in the same model. However, Malcangio et al. (2000) did find $\mathrm{A} \beta$-evoked substance $\mathrm{P}$ release in rats that had undergone spinal nerve lesions. Pitcher and Henry (2004) used a modification of the chronic constriction injury (CCI) model (Bennett and Xie, 1988) and observed touch-evoked afterdischarges in dorsal horn neurons that were apparently driven by myelinated afferents and were blocked by NK1 receptor antagonists. These results suggest that the extent of substance $\mathrm{P}$ upregulation in $\mathrm{A} \beta$ afferents may depend on the type and location of axonal injury. Because substance P excites nociceptive dorsal horn neurons (Salter and Henry, 1991), it has been proposed that upregulation of the peptide in $A \beta$ cutaneous afferents may contribute to allodynia after certain types of nerve injury (Devor, 2005).

In this study, we used three nerve injury models [SNT, CCI, 
and spinal nerve ligation (SNL)] to look for evidence that central terminals of $\mathrm{A} \beta$ afferents contain and/or release substance $\mathrm{P}$ after nerve injuries that give rise to tactile allodynia. Because it has been suggested that CGRP is upregulated in $A \beta$ afferents after nerve injury (Miki et al., 1998; Ma et al., 1999), we also looked for CGRP in central terminals of these afferents.

\section{Materials and Methods}

All experiments were approved by the Ethical Review Process Applications Panel of the University of Glasgow, and were performed in accordance with the European Community directive 86/609/EC and the United Kingdom Animals (Scientific Procedures) Act 1986.

Animals and operative procedures. Experiments were performed on a total of 24 adult male Sprague Dawley rats (Harlan, Loughborough, UK), with body weights between 240 and 320 g. Surgical procedures were performed on 17 of the rats to produce three distinct types of unilateral peripheral nerve injury: SNT $(n=5)$, CCI $(n=6)$, and SNL $(n=6)$. In each of these cases, the surgery was performed under halothane anesthesia. For SNT, the left sciatic nerve was exposed at midthigh level and a 5 $\mathrm{mm}$ length was removed between two ligatures. For CCI, four loose 4-0 chromic catgut ligatures were placed around the left sciatic nerve at midthigh level (Bennett and Xie, 1988). For SNL, the left L5 spinal nerve was tightly ligated $5 \mathrm{~mm}$ distal to the dorsal root ganglion with 4-0 Mersilk (Kim and Chung, 1992). All animals made an uneventful recovery after surgery.

Behavioral testing. Rats that had undergone SNL were tested to detect signs of tactile allodynia, whereas those with CCI were tested for tactile allodynia and thermal hyperalgesia. In each case, the animals were tested on preoperative days 6,3 , and 1 , and on postoperative days $1,4,6,8,11$, and 14. Responses to thermal stimuli were measured with a Plantar Analgesia Instrument (Ugo-Basile, Comerio, Italy) (Hargreaves et al., 1988) as described previously (Polgár et al., 2003) and differences between the two sides were assessed with a one-tailed unpaired $t$ test for each time point. Tests for tactile allodynia were performed with a series of von Frey filaments as described by Polgár et al. (2005). The 50\% paw withdrawal threshold was calculated by using Dixon's nonparametric test (Dixon, 1980; Chaplan et al., 1994), and differences between the two sides at each time point were assessed with a one-tailed Mann-Whitney $U$ test.

Transganglionic labeling of injured sciatic afferents. Two of the rats that had undergone SNT were used to investigate the extent of NPY upregulation in primary afferents in the gracile nucleus, to determine whether NPY was a reliable marker for axotomized myelinated afferent terminals in this region (see below). Eleven days after the SNT procedure, they were reanesthetized with halothane and received injections of $3 \mu \mathrm{l}$ of $1 \%$ cholera toxin B subunit (CTb) (Sigma, Poole, Dorset, UK) into the sectioned left sciatic nerve. They were fixed by perfusion under terminal anesthesia 3 d later (see below).

Stimulation of primary afferents. Electrical stimulation of primary afferents was performed in 10 cases: three CCI and three SNL rats, together with four animals that had not undergone nerve injury operations (unoperated rats). This was done to test whether substance P was released from the stimulated afferents and would internalize NK1 receptors on dorsal horn neurons. For the CCI and SNL rats, the stimulation was performed on the 14th day after the operation. In each case, anesthesia was induced with halothane and subsequently maintained by regular doses of sodium pentobarbitone (Rhône-Mérieux, Harlow, Essex, UK; $10 \mathrm{mg} / \mathrm{kg}$, i.v.), given as required. The depth of anesthesia was initially assessed by monitoring the pedal withdrawal reflexes, the corneal reflex, and blood pressure. The corneal reflex and blood pressure were monitored throughout the duration of the experiment. Animals were then paralyzed with Pancuronium bromide (Pavulon, Faulding, Leamington Spa, UK; $0.3 \mathrm{mg} / \mathrm{kg}$, i.v., every $40 \mathrm{~min}$ ) and ventilated artificially with anesthetic administered at a frequency commensurate with that required before paralysis. Core temperature was maintained close to $38^{\circ} \mathrm{C}$. Mean blood pressure was always $>80 \mathrm{mmHg}$ and $\mathrm{P}_{\mathrm{CO} 2}$ was maintained within the range $4.0-4.5 \%$.

A lumbar laminectomy was performed to expose spinal levels T13 to S1, and either the left sciatic nerve or the left L5 dorsal root was exposed and mounted in continuity on silver bipolar stimulating electrodes. In the rats that had undergone SNL, the L5 dorsal root was stimulated at a strength sufficient to activate $A \beta$ fibers (see below), whereas in the CCI rats, the sciatic nerve was stimulated at $\mathrm{A} \beta$ strength with the cathode placed centrally, $\sim 5 \mathrm{~mm}$ proximal to the lesion. In two unoperated rats, the $\mathrm{L} 5$ dorsal root was stimulated at $\mathrm{A} \beta$ strength ( $\mathrm{A} \beta$ controls), and in an additional two unoperated rats the sciatic nerve was stimulated at a strength sufficient to activate $\mathrm{C}$ fibers (C fiber controls). This last group was used to confirm that the substance $\mathrm{P}$ released from $\mathrm{C}$ fibers caused internalization of NK1 receptors in the dorsal horn. Stimulation at C fiber strength was applied to the sciatic nerve (rather than the L5 dorsal root) to avoid the possibility of direct stimulus spread to the spinal cord.

The exposed spinal cord, and nerve or dorsal root were covered in warm mineral oil, and a silver ball electrode was placed on the lumbar dorsal columns to record afferent volleys and cord dorsum potentials (CDPs) evoked by afferent fiber stimulation. Electrical stimulation was performed at least $1 \mathrm{~h}$ after placing the electrodes to allow for recycling of any NK1 receptors that may have been internalized as a result of nerve manipulation (Allen et al., 1999). To determine an appropriate stimulus intensity for maximal activation of $\mathrm{A} \beta$ afferents, we applied stimuli (duration, $0.2 \mathrm{~ms}$ ) to the nerve while monitoring the $A \beta$-evoked CDP. A stimulus intensity $20-30 \%$ above that found to evoke an $\mathrm{A} \beta \mathrm{CDP}$ of maximal amplitude was used for subsequent stimulation. This method was needed to ensure that all $\mathrm{A} \beta$ afferents in the nerve were excited, because the excitability of myelinated axons may alter after nerve injury. The stimulus strength was up to $10 \mu \mathrm{A}$ for stimulation of the dorsal root and up to $200 \mu \mathrm{A}$ for stimulation of the sciatic nerve. The difference in stimulation intensity required at the two sites is at least partly attributable to the much larger size of the sciatic nerve, compared with the L5 dorsal root. Supramaximal A $\beta$ stimulation ( $0.2 \mathrm{~ms}$ duration) was applied for 5 $\mathrm{min}$ at a frequency of $10 \mathrm{~Hz}$. For the $\mathrm{C}$ fiber controls, stimuli of $10 \mathrm{~mA}$ ( $0.5 \mathrm{~ms}$ duration) were applied for $5 \mathrm{~min}$ at a frequency of $10 \mathrm{~Hz}$. In all cases, animals were maintained under anesthetic for $8 \mathrm{~min}$ after the end of the electrical stimulation, because NK1 receptor internalization has been found to be maximal at this time (Mantyh et al., 1995). They were then fixed by perfusion (see below) under deep anesthesia.

Fixation and sectioning. All of the rats that had undergone nerve injury operations were fixed by perfusion on the 14th day after the operation. This time was chosen because it has been reported that upregulation of substance $\mathrm{P}$ and CGRP in myelinated afferents in the gracile nucleus is maximal at 14 d (Noguchi et al., 1995; Miki et al., 1998). Behavioral signs of neuropathic pain are also well established at this time (Bennett and Xie, 1988; Kim and Chung, 1992). The A $\beta$ and $C$ fiber control groups were also perfused at the end of the stimulation procedure, and an additional three unoperated rats were perfused to allow assessment of NK1 receptor internalization in naive animals. In all cases, rats were deeply anesthetized with pentobarbitone and perfused through the left ventricle with $1000 \mathrm{ml}$ of fixative containing $4 \%$ freshly depolymerized formaldehyde. The L4 and L5 segments of spinal cord and/or the region of caudal medulla containing the gracile nuclei were removed, notched to allow identification of the two sides and postfixed at $4^{\circ} \mathrm{C}$ overnight. They were then cut into $60-\mu \mathrm{m}$-thick transverse sections with a vibratome. The sections were incubated in $50 \%$ ethanol before being processed for immunocytochemistry.

General features of immunocytochemistry and analysis. All immunocytochemical procedures involved incubation of free-floating sections in mixtures of primary antibodies for $48 \mathrm{~h}$, followed by treatment with combinations of species-specific fluorescent secondary antibodies for $24 \mathrm{~h}$, in each case at $4^{\circ} \mathrm{C}$. Secondary antibodies were all raised in donkey and conjugated to either Alexa 488 (Invitrogen, Eugene, OR; 1:500) or Rhodamine Red or Cy5 (Jackson ImmunoResearch, West Grove, PA; 1:100). All antibodies were diluted in PBS containing $0.3 \mathrm{M} \mathrm{NaCl}$ and $0.3 \%$ Triton X-100. In some cases, nuclear staining was performed with $4^{\prime}, 6^{\prime}$-diamidino-2-phenylindole (DAPI) or propidium iodide. Sections were mounted in antifade medium (Vectashield; Vector Laboratories, Peterborough, UK) and stored at $-20^{\circ} \mathrm{C}$.

Sections were scanned with either a MRC 1024 or a Radiance 2100 confocal microscope (Bio-Rad, Hemel Hempstead, UK). All of the quantitative analysis was performed on sections scanned sequentially (to 
avoid fluorescent bleed-through) through a $60 \times$ oil immersion lens. For the gracile nucleus, sections through the broadest part of the nucleus, close to the level of the obex, were analyzed. Myelinated afferents in the L5 dorsal root of the rat that terminate in lamina III extend throughout the rostral one-half of the L5 segment and the whole of the L4 segment (Rivero-Melián and Grant, 1990), and we therefore analyzed sections from this region to ensure optimal sampling of L5 afferent terminals. Sections were analyzed with Neurolucida for confocal software (MicroBrightField, Colchester, VT).

Detection of CTb and NPY in the gracile nucleus after transganglionic labeling. Sections of caudal medulla from the two SNT rats that had received injections of $\mathrm{CTb}$ into the transected sciatic nerve were incubated in goat anti-CTb (List Biologic, Campbell, CA; 1:5000), guinea pig anti-vesicular glutamate transporter 1 (VGLUT1) (Chemicon, Temecula, CA; 1:20,000) and rabbit anti-NPY (Peninsula Laboratories, Belmont, CA; 1:1000), and these were revealed with Alexa 488, Cy5, and Rhodamine Red, respectively.

To confirm the presence of NPY in the central terminals of damaged $\mathrm{A} \beta$ afferent fibers, we initially obtained low-power scans ( $20 \times$ lens) ipsilateral to the nerve injection to identify areas of CTb labeling in the gracile nucleus. Two sections from each of the two rats were then scanned through the $60 \times$ lens, and from the two animals 174 or $198 \mathrm{CTb}$-labeled terminals were examined for NPY immunoreactivity, whereas 231 and 248 NPY-immunoreactive terminals were examined for CTb labeling. In each case, the selection of boutons was made while the observer was blind to the other type of immunostaining.

Substance $P$ and CGRP in terminals of axotomized afferents. To look for substance P and CGRP in the central terminals of injured myelinated afferents, we reacted sections from the caudal medulla and from the L4 and L5 spinal segments from nine rats with a triple-labeling immunocytochemical method. The sections were taken from the three SNT rats that had not received CTb injections, and from the three CCI and three SNL rats that had not undergone electrical nerve stimulation.

Sections were incubated in either of the following: (1) guinea pig antiVGLUT1 $(1: 20,000)$, rabbit anti-NPY (1:1000), and monoclonal rat antisubstance P (Sera-Lab, Crawley Down, UK; 1:100), or (2) guinea pig anti-VGLUT1 (1:20,000), sheep anti-NPY (Chemicon; 1:100), and rabbit anti-CGRP (Affiniti Research Products, Exeter, UK; 1:1000). These were revealed with Cy5, Rhodamine Red, and Alexa 488, respectively.

Sections of caudal medulla and lumbar spinal cord (five sections from each region for each antibody combination per animal) were scanned through areas in which NPY upregulation was evident. Injured $A \beta$ afferents in the gracile nucleus were identified by the presence of NPY (see below), and between 122 and 277 of these were selected from each animal for each antibody combination. The selected boutons were then examined to determine whether they contained substance P or CGRP immunoreactivity. For the spinal cord, boutons in laminas IIi and III that belonged to injured myelinated afferents, identified by the presence of both NPY and VGLUT1 immunoreactivity, were selected (between 63 and 344 from each rat for each antibody combination) and examined for substance P or CGRP immunoreactivity. In all cases, boutons were selected before immunostaining for substance P or CGRP was viewed.

In addition, a search was made for both substance P and CGRP in VGLUT1-immunoreactive boutons in the gracile nucleus (in three sections per animal) and for these peptides in boutons that contained either NPY or VGLUT1 in laminas IIi and III of the spinal cord (three to five sections per animal).

Investigation of NK1 receptor internalization after nerve stimulation. Sections from the L4 and L5 spinal segments of all 10 rats that had undergone electrical nerve stimulation (three CCI, three SNL, two A $\beta$ control, two $\mathrm{C}$ fiber control) and from three additional naive rats were processed to reveal the NK1 receptor. They were incubated in rabbit anti-NK1 receptor (Sigma; 1:10,000), which was revealed with Alexa 488, and were then stained with DAPI or propidium iodide (Todd et al., 1998).

To determine whether selective activation of $\mathrm{A} \beta$ fibers after CCI and SNL released sufficient substance $P$ to internalize NK1 receptors on lamina I neurons, we examined two sections from each of the three CCI and three SNL rats. Tissue from the two $\mathrm{A} \beta$ and two $\mathrm{C}$ fiber control animals and from the three naive rats was also analyzed in the same way. Three adjacent but nonoverlapping fields from within the medial two-thirds of lamina I were scanned through a $60 \times$ lens ( 78 optical sections at a $z$-step of $0.45 \mu \mathrm{m}$ ) from both dorsal horns of each spinal cord section. Image stacks were initially analyzed to identify all NK1 receptor-expressing lamina I neurons for which the nucleus was entirely contained within the stack of confocal images. For each of these cells, the total number of NK1 receptor-immunoreactive endosomes contained within the soma (between sections corresponding to the top and bottom of the nucleus) were identified by using criteria described previously (Mantyh et al., 1995; Allen et al., 1999; Honoré et al., 2000). Endosomes were defined as intensely immunoreactive intracellular organelles between 0.2 and $0.8 \mu \mathrm{m}$ in diameter that were not part of the external cell membrane or in contact with the cell nucleus. The mean number of endosomes per cell body was determined for each side of each animal, and these results were compared by using a one-way ANOVA with Tukey's pairwise comparisons.

We also analyzed large NK1 receptor-immunoreactive neurons in laminas III and IV in the naive animals and on each side of the $\mathrm{A} \beta$ control, C fiber control, CCI, and SNL animals (7-14 sections per ani$\mathrm{mal}$ ). All neurons of this type for which the entire nucleus was contained in a single section were identified, and the number of endosomes in each cell body was counted.

For both parts of this analysis, the observer was blind to the experimental group to which each section belonged.

\section{Results}

\section{Behavior}

All CCI and SNL rats showed similar changes in posture, regardless of the type of surgery performed: the affected paw was held in either an inverted or everted position, with toes plantar-flexed. The foot was often held in the air, and animals avoided prolonged weight bearing on the affected hindpaw.

Results of the tests for thermal hyperalgesia and tactile allodynia are shown in Figure 1. In the animals with CCI, withdrawal latencies of the affected hindpaw to radiant heat were significantly reduced compared with those of the contralateral paw from postoperative day 4 up to day $14(p<0.005$, one-tailed unpaired $t$ test) (Fig. 1a). In these animals, there was a moderate reduction in $50 \%$ withdrawal threshold of the affected hindpaw to mechanical stimulation. This was significantly different from that of the contralateral side from day 4 onward, and reached a threshold of $<10$ g on days 11 and 14 , at which times the difference between the two sides was highly significant $(p<0.005$, one-tailed Mann-Whitney $U$ test). In the animals with SNL, the $50 \%$ withdrawal threshold of the affected hindpaw to mechanical stimulation showed a greater reduction than that seen in the CCI rats, with values $<4$ g on days 6,11 , and 14 (Fig. 1 c). There was a highly significant difference between the responses of the two hindpaws from postoperative day 4 up to day $14(p<0.005$, one-tailed Mann-Whitney $U$ test).

\section{Transganglionic labeling of sectioned sciatic afferents}

In the dorsal horn, the central terminals of all low-threshold myelinated sciatic nerve afferents (but not those of A $\delta$ nociceptors) express VGLUT1 (Todd et al., 2003), and many of these contain NPY after nerve injury (Wakisaka et al., 1991). Although VGLUT1 is moderately depleted in the central terminals of axotomized myelinated afferents in the dorsal horn by 2 weeks after nerve injury, it can still be detected in the great majority of these terminals (Hughes et al., 2004). In the present study, we observed many axonal boutons that showed both VGLUT1 and NPY immunoreactivity in laminas IIi and III in all nerve-injured animals (see below). These presumably correspond to axotomized lowthreshold myelinated afferents. NPY was also strongly upregulated in the ipsilateral gracile nucleus after each type of nerve 

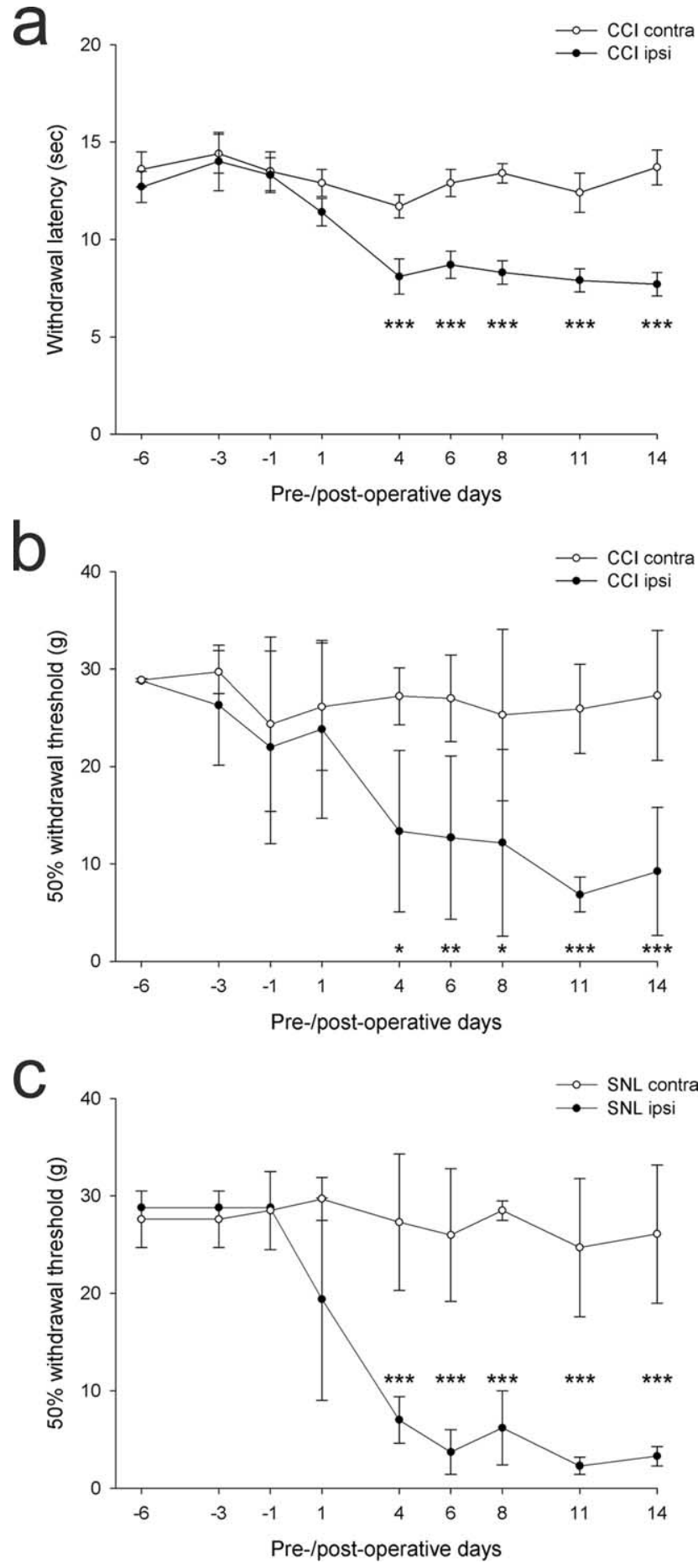

Figure 1. Results of behavioral tests on the CCl and SNL animals. $\boldsymbol{a}$, Means and SEMs for paw withdrawal thresholds to thermal stimulation of the contralateral (contra) and ipsilateral (ipsi) hindpaws in the $\mathrm{Cl}$ animals $(n=6)$ on different preoperative and postoperative days. $\boldsymbol{b}$, Means and SDs for 50\% withdrawal threshold of the ipsilateral and contralateral hindpaw to application of von Frey hairs in the $\mathrm{CCI}$ rats $(n=6)$. c, Means and SDs for $50 \%$ withdrawal threshold of the ipsilateral and contralateral hindpaw to application of von Frey hairs in the SNL rats $(n=6)$. In each case, significant differences between hindpaws are shown as follows: ${ }^{*} p<$ $0.05,{ }^{* *} p<0.01,{ }^{* * *} p<0.005$ (one-tailed unpaired $t$ test for thermal stimulation; one-tailed Mann-Whitney $U$ test for tactile stimulation).

injury (Figs. $2 d, 3 a, b)$. However, we found a substantial reduction of VGLUT1 in the corresponding region (Fig. $2 a, b$ ), and the great majority of NPY-immunoreactive boutons did not show detectable VGLUT1 immunoreactivity (Fig. $2 f-i$ ). The mean percent-
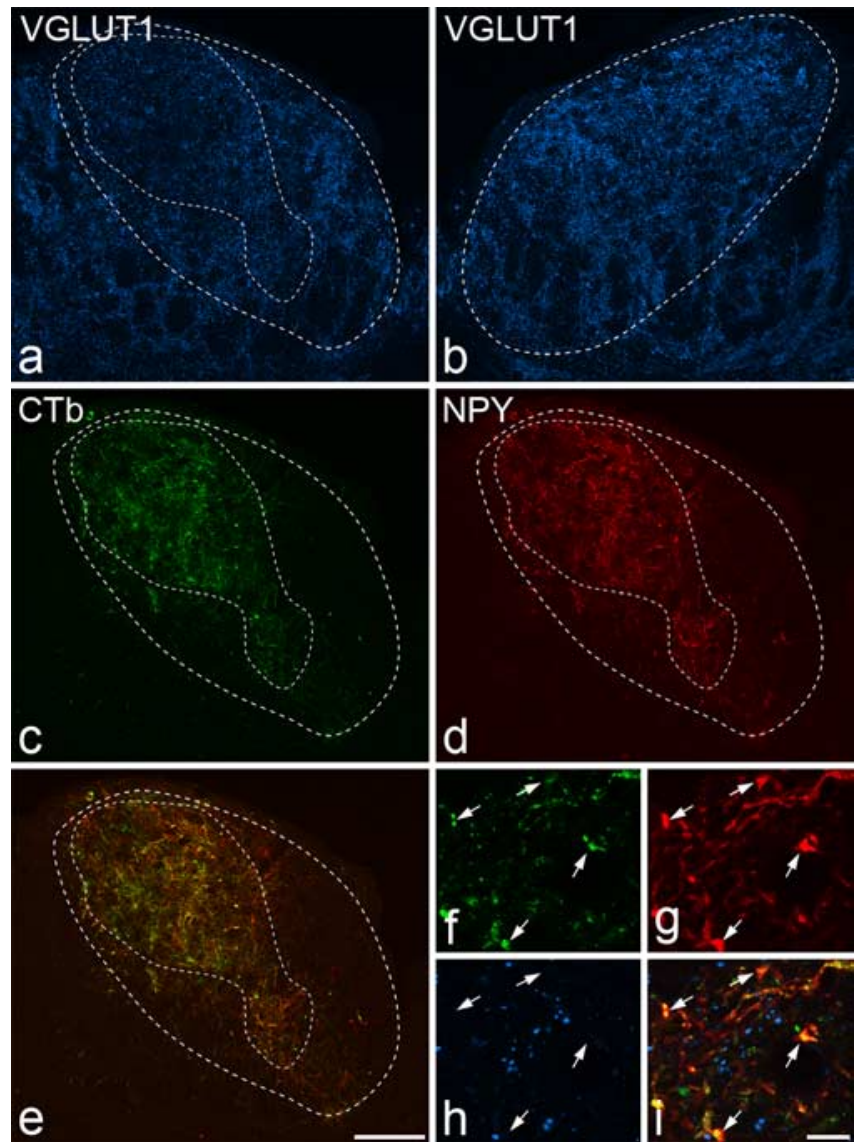

Figure 2. Central patterns of labeling for VGLUT1, CTb, and NPY in the gracile nuclei 2 weeks after unilateral SNT and subsequent CTb injection into the lesioned nerve. $\boldsymbol{a}, \boldsymbol{b}$, VGLUT1 is shown in the ipsilateral ( $\boldsymbol{a}$ ) and contralateral $(\boldsymbol{b})$ gracile nucleus. $\boldsymbol{c}, \boldsymbol{d}$, and e show $(\mathrm{Tb}, \mathrm{NPY}$, and merged $\mathrm{CTb} / \mathrm{NPY}$ labeling in the ipsilateral nucleus, and $\boldsymbol{f}$ - $\boldsymbol{i}$ show a high-magnification view from the ipsilateral nucleus to reveal CTb ( $\boldsymbol{f}), \mathrm{NPY}(\boldsymbol{g})$, VGLUT1 (h), and all three types of immunostaining (i). The outer dashed lines in $\boldsymbol{a}$ and $\boldsymbol{c}-\boldsymbol{e}$, and the dashed line in $\boldsymbol{b}$ represent the outline of the gracile nucleus. The inner dashed line in $\boldsymbol{a}$ and $\boldsymbol{c}-\boldsymbol{e}$ indicates the region in which the majority of NPY-immunoreactive axons were located (as shown in $\boldsymbol{d}$ ). On the ipsilateral side, there is a reduction in VGLUT1 labeling in the area outlined by the inner dashed line (a) compared with that seen on the contralateral side $(\boldsymbol{b})$, and $\mathrm{CTb}$-labeled primary afferent terminals are present in the same area $(\boldsymbol{c})$. (Tb labeling and NPY expression are found in directly overlapping areas in the ipsilateral gracile nucleus $(\boldsymbol{e})$. High-magnification views show colocalization of $\mathrm{CTb}(\boldsymbol{f})$ and $\operatorname{NPY}(\boldsymbol{g})$ in lesioned primary afferent terminals (some indicated by arrows), but these have no detectable VGLUT1 (h). Scale bars: $\boldsymbol{a}-\boldsymbol{e}, 100 \mu \mathrm{m} ; \boldsymbol{f}-\boldsymbol{i}, 10 \mu \mathrm{m}$.

ages of NPY-immunoreactive terminals in the ipsilateral gracile nucleus that were also VGLUT1 immunoreactive in SNT, CCI, and SNL animals were 20.3 (range, 2.3-34.8), 17.1 (9.5-24.8), and 17.4 (1.5-37.9), respectively. Because NPY is only seen in the gracile nucleus after axotomy (Zhang et al., 1993), the most likely explanation for this is that VGLUT1 is depleted to below the threshold for detection in the terminals of most axotomized myelinated afferents in this region. To confirm that the NPY was located in axotomized afferents, we compared immunostaining for CTb and NPY in the gracile nucleus in the two SNT rats that had received injections of $\mathrm{CTb}$ into the transected sciatic nerve. The two types of immunostaining occupied corresponding areas within the nucleus (Fig. $2 c, d$ ), and most of the terminals that were labeled with CTb in each animal were found to express NPY (93 and $86 \%$ ), while the majority of NPY terminals were labeled with CTb (80 and 94\%). However, few of the NPY/CTbimmunoreactive boutons were stained with the VGLUT1 anti- 

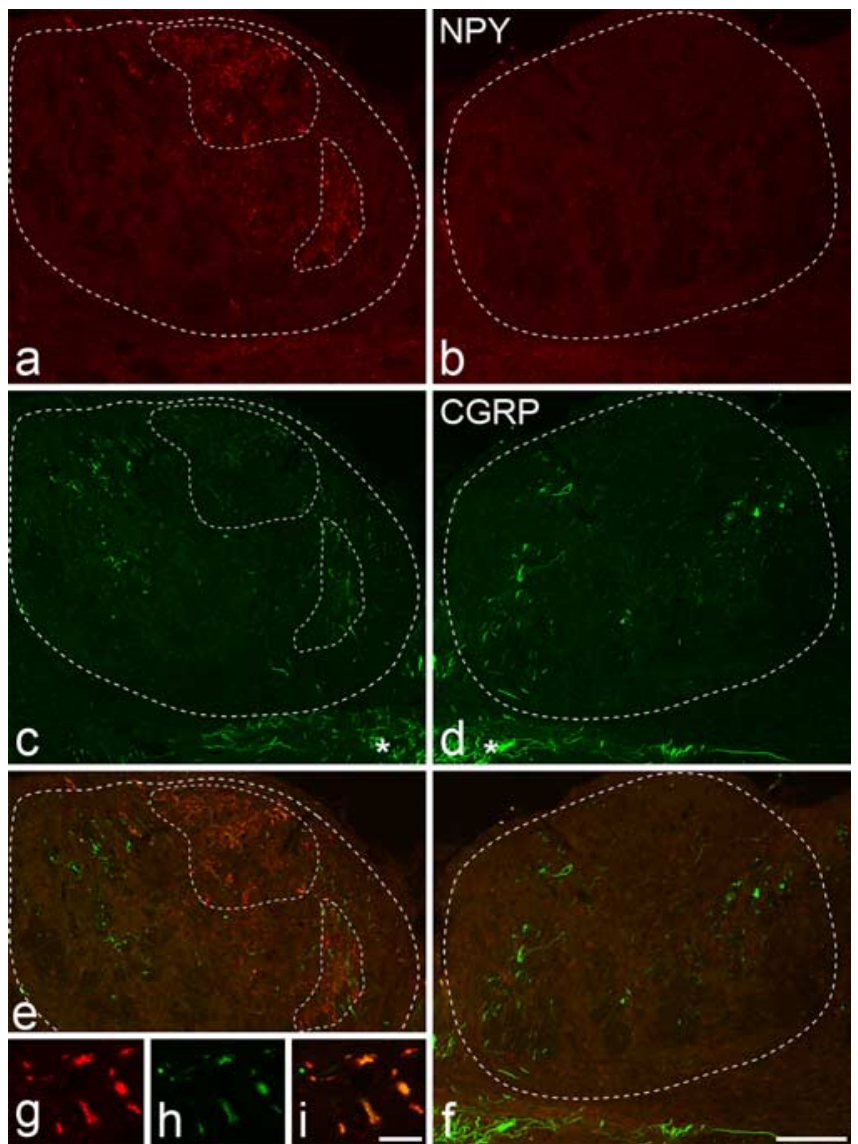

Figure 3. NPY and CGRP immunostaining in the gracile nuclei $14 \mathrm{~d}$ after unilateral $\mathrm{L} 5$ spinal nerve ligation. $\boldsymbol{a}-\boldsymbol{i}$, NPY immunoreactivity $(\boldsymbol{a}, \boldsymbol{b}, \boldsymbol{g})$, CGRP immunoreactivity $(\boldsymbol{c}, \boldsymbol{d}, \boldsymbol{h})$, and merged images $(\boldsymbol{e}, \boldsymbol{f}, \boldsymbol{i})$ from ipsilateral $(\boldsymbol{a}, \boldsymbol{c}, \boldsymbol{e}, \boldsymbol{g}-\boldsymbol{i})$ and contralateral $(\boldsymbol{b}, \boldsymbol{d}, \boldsymbol{f})$ gracile nuclei are shown. The outer dashed lines in $\boldsymbol{a}, \boldsymbol{c}$, and $\boldsymbol{e}$, and the dashed lines in $\boldsymbol{b}, \boldsymbol{d}$, and $\boldsymbol{f}$ represent the outline of the gracile nucleus. Unilateral upregulation of NPY is seen in the ipsilateral nucleus (areas outlined by inner dashed lines in $\boldsymbol{a}$ ). Scattered (GRP-immunoreactive axons are present in both gracile nuclei, but in the area of NPY upregulation numerous weakly positive CGRP terminals are present $(\boldsymbol{c})$. The merged images show that many of the NPY-immunoreactive profiles also contain CGRP $(\boldsymbol{e}, \boldsymbol{i})$. The asterisks in $\boldsymbol{c}$ and $\boldsymbol{d}$ show CGRP-immunoreactive axons in the solitary tract. Scale bars: $\boldsymbol{a}-\boldsymbol{f}, 100 \mu \mathrm{m} ; \boldsymbol{g}-\boldsymbol{i}, 10 \mu \mathrm{m}$.

body (Fig. $2 f-i$ ). NPY was not detected in the gracile nucleus on the contralateral side after any of the nerve injuries (Fig. $3 b$ ).

\section{Substance $P$ and CGRP in the ipsilateral gracile nucleus after} nerve injury

Although we found limited coexistence of VGLUT1 and NPY in axon terminals in the ipsilateral gracile nucleus after nerve injury, the results obtained from the CTb-injected SNT rats indicate that at least the great majority of NPY-immunoreactive boutons in the ipsilateral gracile nucleus belong to axotomized primary afferents. We therefore used the presence of NPY to identify axotomized primary afferent terminals in the gracile nucleus after each type of nerve injury.

A few boutons and fibers with strong CGRP immunoreactivity were found scattered throughout both the ipsilateral and contralateral gracile nuclei in all nerve-injured animals, and the density of these did not appear to differ between the two sides (Fig. $3 c, d)$. This distribution resembles that seen in the gracile nucleus of normal rats and cats (Fabri and Conti, 1990; Ma and Bisby, 1998). In each nerve injury model, many of the NPYimmunoreactive boutons in the ipsilateral gracile nucleus also showed CGRP immunoreactivity (Fig. 3). However, the CGRP
Table 1. CGRP and substance P expression in NPY-positive boutons in the ipsilateral gracile nucleus in different nerve injury models

\begin{tabular}{|c|c|c|c|c|c|}
\hline \multirow[b]{2}{*}{ Model } & \multirow[b]{2}{*}{ Animal } & \multicolumn{2}{|l|}{ CGRP } & \multicolumn{2}{|l|}{ Substance P } \\
\hline & & NPY boutons tested & $\%$ Positive & NPY boutons tested & $\%$ Positive \\
\hline \multirow[t]{4}{*}{ SNT } & 1 & 128 & 39.8 & 191 & 0 \\
\hline & 2 & 169 & 26.7 & 209 & 0 \\
\hline & 3 & 146 & 28.1 & 205 & 0.5 \\
\hline & Mean & & 31.5 & & 0.2 \\
\hline \multirow[t]{4}{*}{$\mathrm{CCl}$} & 1 & 221 & 71.9 & 169 & 0 \\
\hline & 2 & 159 & 71.1 & 210 & 2.4 \\
\hline & 3 & 180 & 60.0 & 277 & 2.2 \\
\hline & Mean & & 67.7 & & 1.5 \\
\hline \multirow[t]{4}{*}{ SNL } & 1 & 129 & 50.4 & 193 & 1.6 \\
\hline & 2 & 165 & 55.8 & 133 & 3.0 \\
\hline & 3 & 122 & 62.3 & 200 & 1.0 \\
\hline & Mean & & 56.1 & & 1.9 \\
\hline
\end{tabular}
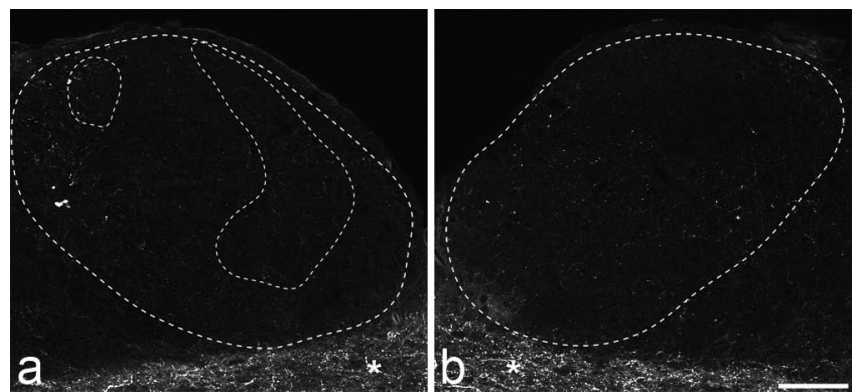

Figure 4. $\quad \boldsymbol{a}, \boldsymbol{b}$, Substance $P$ immunostaining in the ipsilateral $(\boldsymbol{a})$ and contralateral $(\boldsymbol{b})$ gracile nuclei $14 \mathrm{~d}$ after unilateral $\mathrm{L} 5 \mathrm{spinal}$ nerve ligation. The outer dashed line in $\boldsymbol{a}$ and the dashed line in $\boldsymbol{b}$ represent the outline of the gracile nucleus. NPY was upregulated in the ipsilateral gracile nucleus in the region outlined by the two inner dashed lines (data not shown). Very few substance P-immunoreactive profiles were seen in either gracile nucleus, and there was no detectable upregulation of substance $P$ in the areas in which NPY immunostaining was present $(\boldsymbol{a})$. The asterisks in $\boldsymbol{a}$ and $\boldsymbol{b}$ show substance $P$-immunoreactive axons in the solitary tract. Scale bar, $100 \mu \mathrm{m}$.

immunostaining of these terminals was considerably weaker than that seen in the scattered terminals described above. The mean percentages of NPY-immunoreactive terminals that were also CGRP immunoreactive were 31.5 for SNT rats, 67.7 for CCI rats, and 56.1 for SNL rats (Table 1). One-way ANOVA with post hoc Tukey's pairwise comparisons showed that the frequency of expression of CGRP in lesioned terminals after SNT was significantly different from those after CCI and SNL $(p<0.005)$.

Although strong staining for substance $\mathrm{P}$ was seen in various structures in the medulla, including the spinal trigeminal nucleus and the nucleus of the solitary tract, we found very few substance $\mathrm{P}$-immunoreactive profiles in the gracile nucleus on either side after nerve injury (Fig. 4). Very weak substance P immunoreactivity was observed in a small proportion of NPYimmunoreactive boutons (data not shown). The mean percentages of NPY-immunoreactive terminals that were substance P immunoreactive were 0.2 for SNT rats, 1.5 for CCI rats, and 1.9 for SNL rats (Table 1). One-way ANOVA with post hoc Tukey's pairwise comparisons showed these values were not significantly different. Neither substance P nor CGRP immunoreactivity was detected in VGLUT1 terminals that did not express NPY.

In these experiments, we used a well characterized monoclonal substance P antibody (Cuello et al., 1979), but this was different from that used by Noguchi et al. (1995). To confirm that this 

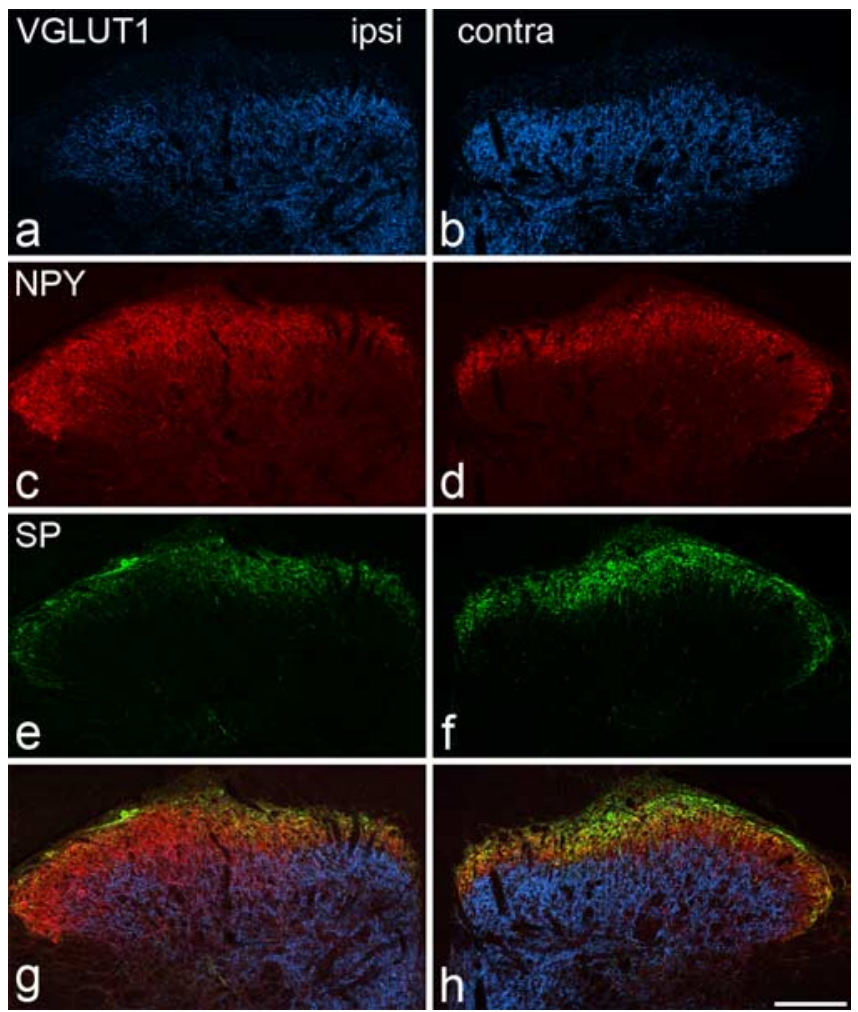

Figure 5. VGLUT1, NPY, and substance $P$ immunostaining in the lumbar spinal cord $14 \mathrm{~d}$ after unilateral L5 spinal nerve ligation. $\boldsymbol{a}-\boldsymbol{h}$, The figure shows VGLUT1 $(\boldsymbol{a}, \boldsymbol{b}), \operatorname{NPY}(\boldsymbol{c}, \boldsymbol{d})$, substance P (SP) $(\boldsymbol{e}, \boldsymbol{f})$, and merged images $(\boldsymbol{g}, \boldsymbol{h})$ on the ipsilateral (ipsi) $(\boldsymbol{a}, \boldsymbol{c}, \boldsymbol{e}, \boldsymbol{g})$ and contralateral (contra) $(\boldsymbol{b}, \boldsymbol{d}, \boldsymbol{f}, \boldsymbol{h})$ sides. VGLUT1 staining reveals a band of immunoreactive axons that occupies the deeper part of the dorsal horn (extending ventrally from lamina Ili), and the staining is weaker on the ipsilateral side because of depletion of VGLUT1 from injured primary afferent terminals. NPY immunostaining is normally concentrated in laminas I-I (d), but is increased in a region just ventral to this, corresponding to lamina III, on the ipsilateral side (c). Substance $P$ is normally present in laminas $I-\|(\boldsymbol{f})$, but there is reduced immunostaining on the ipsilateral side (e). Scale bar, $100 \mu \mathrm{m}$.

did not account for the discrepancy, we also reacted some sections with the antibody used by Noguchi et al. (1995) and revealed this with immunofluorescence and immunoperoxidase methods. However, we saw no evidence of increased substance $\mathrm{P}$ immunoreactivity in the ipsilateral gracile nucleus with either method.

\section{Substance $P$ and CGRP in the ipsilateral dorsal horn after nerve injury}

Low-magnification examination of spinal cord sections from SNT and CCI animals showed that NPY was upregulated in laminas IIi and III, especially in the central part of the ipsilateral dorsal horn, resembling the pattern that has been described after sciatic nerve transection (Wakisaka et al., 1991; Zhang et al., 1993). In SNL rats, the region of NPY upregulation extended more laterally (Fig. $5 c, d$ ). In all three models, there was a modest depletion of VGLUT1 from laminas IIi-III in the region corresponding to that of increased NPY, and there was also a reduction of substance $\mathrm{P}$ and CGRP immunostaining from the superficial dorsal horn (Fig. 5).

As stated above, many of the NPY-immunoreactive boutons in laminas IIi and III were also VGLUT1 immunoreactive. However, none of these was immunoreactive with antibody against either substance P or CGRP (Fig. 6). The mean numbers of NPY/ VGLUT1-immunoreactive terminals per animal that were exam- ined for CGRP immunoreactivity in the SNT, CCI, and SNL groups were 242,220 , and 183 , respectively $(n=3$ rats for each model). The corresponding numbers per animal examined for substance P immunoreactivity were 299,246 , and 154 . Substance $\mathrm{P}$ and CGRP were very seldom observed in boutons that contained VGLUT1 but not NPY ( 0 of 1160 for substance P, 3 of 1260 for CGRP; data pooled for three SNT, three CCI, and three SNL rats) or in those that contained NPY and not VGLUT1 (1 of 1290 for substance P, 5 of 1100 for CGRP; data pooled for three SNT, three CCI, and three SNL rats).

\section{NK1 receptor internalization after electrical nerve stimulation}

In naive rats, the pattern of NK1 receptor immunoreactivity in the dorsal horn was similar to that described previously (Nakaya et al., 1994; Brown et al., 1995). Immunostaining was observed on the surfaces of many cell bodies and dendrites in lamina I and on scattered large neurons with cell bodies in laminas III or IV and dendrites that entered the superficial dorsal horn. Although NK1 receptor-immunoreactive cell bodies were occasionally seen in lamina II, these were invariably small and very weakly stained. A similar distribution of NK1 receptor immunostaining was observed in the CCI and SNL rats, although in these animals the staining appeared to be stronger on the side ipsilateral to the nerve injury.

After nerve stimulation at $\mathrm{A} \beta$ strength, the sections from $\mathrm{CCI}$ and SNL animals, as well as those from the $\mathrm{A} \beta$ control rats, did not show any signs of NK1 receptor internalization in lamina I (Fig. 7). The mean numbers of endosomes observed in the selected NK1 receptor-immunoreactive cell bodies in lamina I in the different experimental groups are shown in Table 2. The mean numbers of endosomes per cell on the ipsilateral side in the CCI and SNL models were 1.0 and 0.6 , respectively, and these were similar to the values for the contralateral sides in these animals, each side of the $A \beta$ control group, and the naive rats. None of the NK1 receptor-immunoreactive lamina I cells from either side of any of the CCI, SNL, A $\beta$ control and naive animals were classified as having undergone internalization (20 or more somatic endosomes per cell) (Mantyh et al., 1995). In contrast, on the ipsilateral side in the $\mathrm{C}$ fiber control group, all of the NK1 receptor lamina I neurons examined showed numerous endosomes, and were classified as having undergone internalization (Table 2, Fig. 7b). One-way ANOVA with post hoc Tukey's pairwise comparisons showed that the difference between the ipsilateral side of the $\mathrm{C}$ fiber controls and all other groups was significant $(p<0.001)$, whereas no significant difference was detected between any of the other groups.

Results of the analysis of the lamina III-IV NK1 receptorimmunoreactive neurons are shown in Table 3, and examples of immunostaining are shown in Figure 8. Very few endosomes were observed in these neurons on either side in any of the groups examined, except for the ipsilateral side of the $\mathrm{C}$ fiber controls, in which all of the cells were classified as having undergone internalization. Again, one-way ANOVA with post hoc Tukey's pairwise comparisons showed that the difference between the ipsilateral side of the $\mathrm{C}$ fiber controls and all other groups was significant $(p<0.001)$, whereas no significant difference was detected between any of the other groups.

\section{Discussion}

There have been several reports that substance $\mathrm{P}$ is upregulated in A $\beta$ afferents after nerve injury (Marchand et al., 1994; Noguchi et al., 1994, 1995; Fukuoka et al., 1998) or inflammation (Neumann 

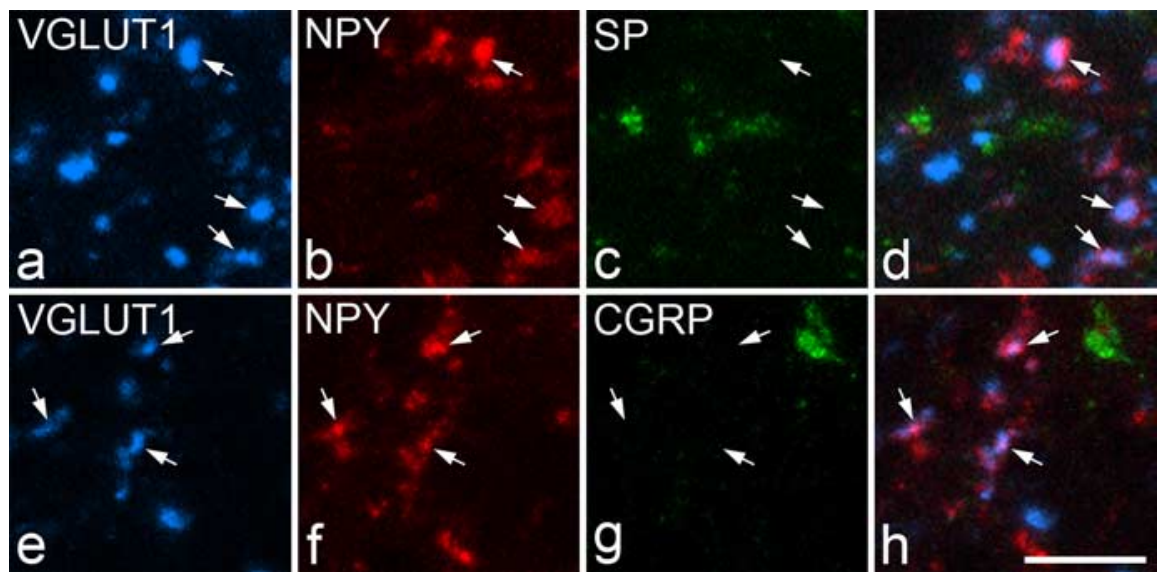

Figure 6. VGLUT1, NPY, substance P (SP), and CGRP immunolabeling in boutons in lamina III of the ipsilateral lumbar spinal cord after unilateral L5 spinal nerve ligation. $\boldsymbol{a}-\boldsymbol{d}$ show a single field scanned for VGLUT1, NPY, and substance P. NPY and VGLUT1 are colocalized in several boutons (some indicated with arrows), which belong to injured myelinated afferents. However, substance $P$ immunoreactivity is not present in any of these $(\boldsymbol{c}, \boldsymbol{d})$. $\boldsymbol{e}-\boldsymbol{h}$ show another field scanned for VGLUT1, NPY, and CGRP. Again, NPY and VGLUT1 are colocalized in certain boutons (some indicated with arrows), but these do not contain (GRP immunoreactivity $(\boldsymbol{g}, \boldsymbol{h})$. Images were obtained from stacks of five $(\boldsymbol{a}-\boldsymbol{d})$ or three $(\boldsymbol{e}-\boldsymbol{h})$ optical sections at $0.5 \mu \mathrm{m} z$-separation. Scale bar, $5 \mu \mathrm{m}$.
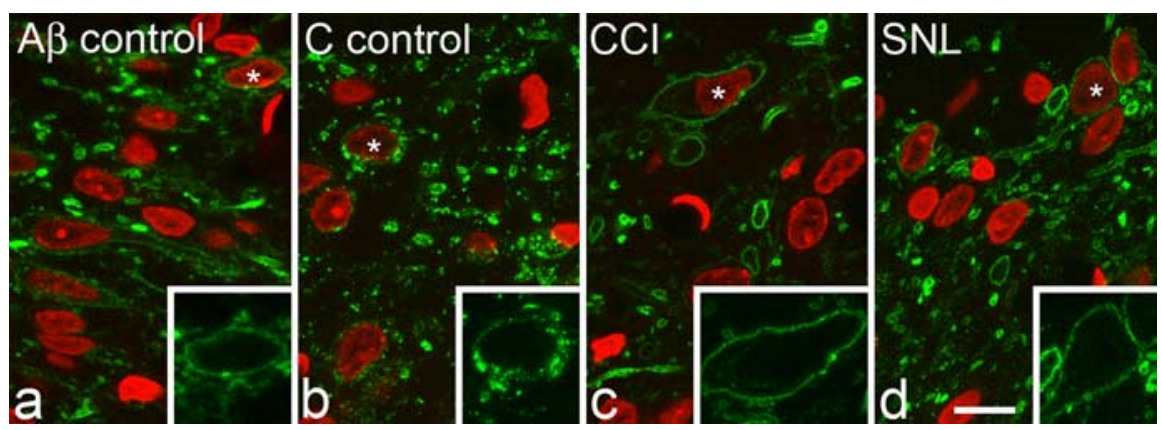

Figure 7. NK1 receptor immunostaining in lamina I after electrical nerve stimulation. Sections were scanned to reveal NK1 receptor (green) and DAPI (red). $\boldsymbol{a}$ and $\boldsymbol{b}$ are taken from unoperated animals stimulated at $A \beta$ and $($ fiber strength, respectively. cand $\boldsymbol{d}$ are from animals that had undergone $\mathrm{CCl}$ or SNL $14 \mathrm{~d}$ previously and were stimulated at A $\beta$ strength. In each case, the inset shows NK1 receptor immunostaining on one of the cells from the main image (identified with an asterisk) at a higher magnification. Significant internalization of the NK1 receptor (indicated by the presence of numerous endosomes) is only seen in the case in which ( fibers were stimulated $(\boldsymbol{b})$. Each image shows a projection of three optical sections at $0.45 \mu \mathrm{m} z$-spacing. Scale bar, $10 \mu \mathrm{m}$.
SNT (Hughes et al., 2004). Colocalization of VGLUT1 and NPY therefore allowed us to identify boutons belonging to injured myelinated afferents. It is likely that VGLUT1 was depleted to below detection threshold in terminals of some axotomized $\mathrm{A} \beta$ afferents in the dorsal horn. However, our failure to find substance $P$ or CGRP in significant numbers of NPY+/VGLUT1 - boutons suggests that neither of these peptides was upregulated in these terminals.

NPY is not normally expressed in the gracile nucleus, but appears after nerve injury in boutons presumed to belong to damaged myelinated afferents (Zhang et al., 1993). However, VGLUT1 was detected in only $17-20 \%$ of NPY-containing terminals in nerve-injured animals. To confirm that NPY-containing axons were primary afferents, we injected CTb into the transected sciatic nerve in two rats and found that most $(80-94 \%)$ were CTb immunoreactive, and $\sim 90 \%$ of CTb-labeled afferents expressed NPY. Unmyelinated afferents can transport CTb after nerve injury (Tong et al., 1999; Bao et al., 2002; Shehab et al., 2003). However, these project sparsely to the gracile nucleus (Giuffrida and Rustioni, 1992) and most NPY-expressing axotomized afferents are thought to have myelinated axons (Shehab et al., 2003). It is therefore likely that most (if not all) NPY-immunoreactive boutons in the gracile nucleus belonged to damaged myelinated afferents, and that NPY was expressed by the great majority of these.

\section{Comparison with previous anatomical studies}

et al., 1996). Although Allen et al. (1999) failed to detect substance $P$ release from $A \beta$ afferents after SNT or inflammation, two studies have suggested that this occurs in neuropathic models (Malcangio et al., 2000; Pitcher and Henry, 2004).

Our results suggest that, although nerve injury does induce modest upregulation of CGRP in $\mathrm{A} \beta$ afferents in gracile nucleus, neither SNL nor CCI leads to detectable levels of substance P in $\mathrm{A} \beta$ terminals in gracile nucleus or dorsal horn. We also found that these injuries do not result in NK1 receptor internalization in dorsal horn neurons after stimulation of injured $\mathrm{A} \beta$ fibers.

\section{Identification of terminals of injured afferents}

$\mathrm{A} \beta$ terminals can be revealed with $\mathrm{CTb}$, a selective marker for myelinated afferents (Robertson and Grant, 1985; Rivero-Melián and Grant, 1990). However, we avoided using CTb in case this interfered with transport of substance P or CGRP. We therefore tested the suitability of NPY as a marker for terminals of injured myelinated afferents. VGLUT1 is found in central terminals of all low-threshold myelinated afferents in spinal cord and is not normally colocalized with NPY (Todd et al., 2003). Although VGLUT1 is depleted after nerve injury, it can still be detected in most myelinated afferent terminals in laminas III-V 2 weeks after
Two approaches have been used to investigate substance $\mathrm{P}$ and CGRP upregulation in axotomized myelinated afferents: in situ hybridization and immunocytochemistry. Several studies have demonstrated increased mRNA for these peptides in large dorsal root ganglion cells after nerve injury, and at least some of these cells project to the gracile nucleus (Marchand et al., 1994; Noguchi et al., 1994, 1995; Fukuoka et al., 1998; Miki et al., 1998). Immunocytochemical findings are less clearcut. After SNT, Noguchi et al. (1995) reported increased substance P immunoreactivity in ipsilateral gracile nucleus, but no change in laminas III-IV of the dorsal horn, and Miki et al. (1998) found increased CGRP immunoreactivity in both areas after spinal nerve transections. However, Ma and Bisby (1998) showed increased CGRP in ipsilateral gracile nucleus, but depletion from deep dorsal horn after SNT or CCI.

We observed weak CGRP immunoreactivity in many NPYcontaining axons in ipsilateral gracile nucleus after nerve injury. The proportion was higher after CCI and SNL, which suggests that this may have a role in neuropathic pain. However, we saw very little staining for substance $\mathrm{P}$ in the gracile nucleus after any nerve injury.

The situation in spinal cord is complicated by the presence of 
Table 2. Numbers of endosomes in lamina I NK1 receptor-immunoreactive neurons

\begin{tabular}{|c|c|c|c|c|c|c|c|}
\hline \multirow[b]{2}{*}{ Model } & \multirow[b]{2}{*}{ Animal } & \multicolumn{3}{|l|}{ Ipsilateral } & \multicolumn{3}{|l|}{ Contralateral } \\
\hline & & Cells sampled & Mean number of endosomes per cell & $\%$ Cells internalized & Cells sampled & Mean number of endosomes per cell & $\%$ Cells internalized \\
\hline \multirow[t]{4}{*}{ Naive } & 1 & 40 & 0.5 & 0 & & & \\
\hline & 2 & 43 & 0.6 & 0 & & & \\
\hline & 3 & 52 & 0.5 & 0 & & & \\
\hline & Mean & & 0.5 & 0 & & & \\
\hline \multirow[t]{3}{*}{$A \beta$ control } & 1 & 24 & 2.9 & 0 & 37 & 0.9 & 0 \\
\hline & 2 & 32 & 1.8 & 0 & 41 & 0.9 & 0 \\
\hline & Mean & & 2.3 & 0 & & 0.9 & 0 \\
\hline \multirow[t]{4}{*}{$\mathrm{A} \beta \mathrm{CCl}$} & 1 & 19 & 1.0 & 0 & 25 & 1.2 & 0 \\
\hline & 2 & 38 & 0.6 & 0 & 31 & 1.7 & 0 \\
\hline & 3 & 43 & 1.3 & 0 & 35 & 1.1 & 0 \\
\hline & Mean & & 1.0 & 0 & & 1.3 & \\
\hline \multirow[t]{4}{*}{$A \beta S N L$} & 1 & 39 & 1.0 & 0 & 40 & 1.4 & 0 \\
\hline & 2 & 50 & 0.2 & 0 & 37 & 0.1 & 0 \\
\hline & 3 & 36 & 0.6 & 0 & 47 & 0.7 & 0 \\
\hline & Mean & & 0.6 & 0 & & 0.7 & 0 \\
\hline \multirow[t]{3}{*}{ C control } & 1 & 31 & 117.8 & 100 & 37 & 0.8 & 0 \\
\hline & 2 & 32 & 106.8 & 100 & 22 & 0.8 & 0 \\
\hline & Mean & & 112.3 & 100 & & 0.8 & 0 \\
\hline
\end{tabular}

This table shows the numbers of endosomes identified in cell bodies of the selected lamina I NK1 receptor-immunoreactive neurons. Naive animals received no electrical stimulation, and results from the two sides of the spinal cords of these animals were pooled. All other groups were stimulated at A $\beta$ strength on the ipsilateral side, except for the " $C$ control" group, which were stimulated at C fiber strength on the ipsilateral side. For additional details, see Materials and Methods. Cells with $>20$ endosomes were defined as "internalized." One-way ANOVA with post hoc Tukey's pairwise comparisons showed that the difference between the ipsilateral side of the C control group and all other sides/groups was significant $(p<0.001)$, whereas no difference was detected between other sides or groups.

Table 3. Numbers of endosomes in NK1 receptor-immunoreactive neurons in laminas III-IV

\begin{tabular}{|c|c|c|c|c|c|c|c|}
\hline \multirow[b]{2}{*}{ Model } & \multirow[b]{2}{*}{ Animal } & \multicolumn{3}{|l|}{ Ipsilateral } & \multicolumn{3}{|l|}{ Contralateral } \\
\hline & & Cells sampled & Mean number of endosomes per cell & $\%$ Cells internalized & Cells sampled & Mean number of endosomes per cell & $\%$ Cells internalized \\
\hline \multirow[t]{6}{*}{ Naive } & 1 & 7 & 1.9 & 0 & & & \\
\hline & 2 & 6 & 0.7 & 0 & & & \\
\hline & 3 & 15 & 0.5 & 0 & & & \\
\hline & Mean & & 1 & 0 & & & \\
\hline & 1 & 6 & 4.2 & 0 & 11 & 2 & 0 \\
\hline & 2 & 9 & 2.3 & 0 & 7 & 1.7 & 0 \\
\hline$A \beta$ control & Mean & & 3.2 & 0 & & 1.9 & 0 \\
\hline \multirow[t]{4}{*}{$A \beta C C l$} & 1 & 8 & 0.4 & 0 & 7 & 0 & 0 \\
\hline & 2 & 7 & 1.4 & 0 & 4 & 2 & 0 \\
\hline & 3 & 10 & 2.1 & 0 & 6 & 2.7 & 0 \\
\hline & Mean & & 1.3 & 0 & & 1.6 & 0 \\
\hline \multirow[t]{4}{*}{$A \beta S N L$} & 1 & 13 & 3.2 & 0 & 8 & 0.6 & 0 \\
\hline & 2 & 7 & 0.3 & 0 & 7 & 0.6 & 0 \\
\hline & 3 & 8 & 1.4 & 0 & 7 & 4 & 0 \\
\hline & Mean & & 1.6 & 0 & & 1.7 & 0 \\
\hline \multirow[t]{3}{*}{ C control } & 1 & 8 & 221 & 100 & 8 & 4.3 & 0 \\
\hline & 2 & 9 & 265.7 & 100 & 8 & 2.9 & 0 \\
\hline & Mean & & 243 & 100 & & 3.6 & 0 \\
\hline
\end{tabular}

This table shows the numbers of endosomes identified in cell bodies of the lamina III-IV NK1 receptor-immunoreactive neurons. Naive animals received no electrical stimulation, and results from the two sides of the spinal cords of these animals were pooled. All other groups were stimulated at A $\beta$ strength on the ipsilateral side, except for the C control group, which were stimulated at C fiber strength on the ipsilateral side. For additional details, see Materials and Methods. Cells with $>20$ endosomes were defined as internalized. One-way ANOVA with post hoc Tukey's pairwise comparisons showed that the difference between the ipsilateral side of the C control group and all other sides/groups was significant $(p<0.001)$, whereas no difference was detected between other sides or groups.

substance $\mathrm{P}$ and CGRP in fine-diameter afferents, some of which terminate in deep laminas, and of substance $\mathrm{P}$ in nonprimary axons. By examining boutons with both VGLUT1 and NPY, we were able to exclude these populations and show that none of those belonging to injured myelinated afferents contained detectable levels of either peptide. Because myelinated afferents that terminate in gracile nucleus are a subpopulation of those in dorsal horn, our results suggest that different boutons belonging to the same afferent differ in terms of peptide upregulation and VGLUT1 depletion.

\section{NK1 receptor internalization}

Although immunocytochemistry failed to show substance P in myelinated afferent terminals in dorsal horn, peptide release could occur at a rate preventing accumulation in terminals. We therefore looked for NK1 receptor internalization after $\mathrm{A} \beta$ stim- 

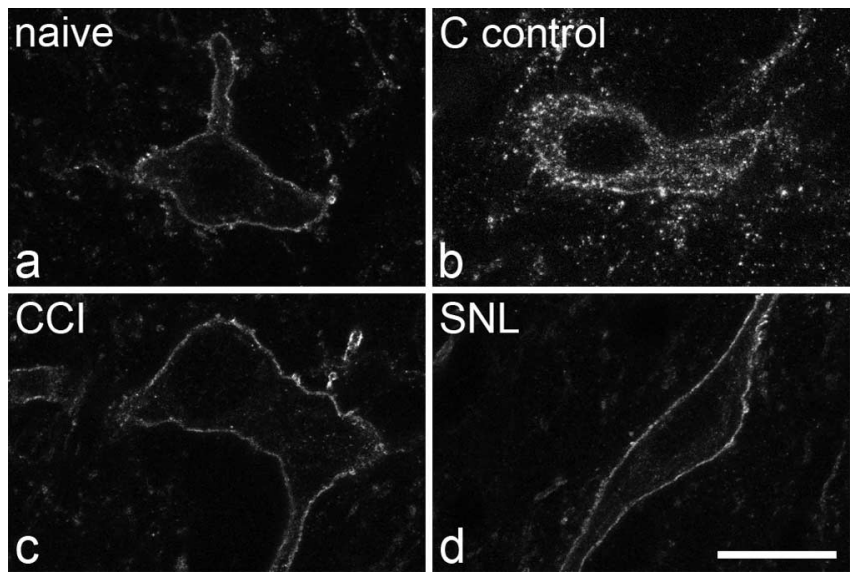

Figure 8. NK1 receptor immunostaining on large lamina III neurons. $\boldsymbol{a}-\boldsymbol{d}$, The scans show parts of the cell bodies of neurons in an unstimulated (naive) animal ( $\boldsymbol{a})$, an unoperated animal stimulated at $C$ fiber strength $(\boldsymbol{b})$, a $\mathrm{CCl}$ animal stimulated at $A \beta$ strength (c), and a SNL anima stimulated at $A \beta$ strength (d). Note the lack of significant internalization in the naive, $\mathrm{CCl}$, and SNL animals and the presence of numerous endosomes in the animal stimulated at C fiber strength. Each image shows a projection of three optical sections at $0.45 \mu \mathrm{m} z$-spacing. Scale bar, $10 \mu \mathrm{m}$.

ulation in different nerve injury models. We examined two populations of cells with high levels of NK1 receptor, neurons in laminas I and III/IV. All of the lamina III/IV and many of the lamina I cells are projection neurons (Todd et al., 2000; Spike et al., 2003). The lamina III/IV cells are located within the termination zone of $\mathrm{A} \beta$ afferents and probably receive synaptic input from these axons (Naim et al., 1998). Although central arbors of $\mathrm{A} \beta$ afferents only extend dorsally to lamina IIi, this is $<100 \mu \mathrm{m}$ from lamina I. For both populations, we saw no increase in the number of endosomes after $\mathrm{A} \beta$ stimulation in CCI or SNL rats. This suggests that any release of substance $\mathrm{P}$ from $\mathrm{A} \beta$ afferents after these injuries is below the level needed to activate significant numbers of NK1 receptors on projection neurons. A possible reason for the difference between our results and those of Malcangio et al. (2000) is that they ligated three spinal nerves rather than one. However, our SNL rats showed clear signs of tactile allodynia, which cannot be explained by release of substance $\mathrm{P}$ from $\mathrm{A} \beta$ afferents.

\section{Substance $P$ and allodynia in neuropathic pain}

There has been considerable debate about the mechanisms that underlie tactile allodynia after nerve injury. There is evidence that this is mediated, at least in part, by $\mathrm{A} \beta$ afferents in both human (Campbell et al., 1988; Gracely et al., 1992; Ochoa and Yarnitsky, 1993) and rat (Field et al., 1999). Several studies have shown that NK1 receptor antagonists reduce tactile allodynia after nerve injury (Campbell et al., 1998; Cumberbatch et al., 1998; Cahill and Coderre, 2002), and this has led to the suggestion that substance $\mathrm{P}$ upregulation in myelinated low-threshold afferents is at least partially responsible. Two possible explanations based on this assumption have been proposed. Devor (2005) has suggested that release of the peptide from ectopically firing axotomized $\mathrm{A} \beta$ afferents could trigger and maintain central sensitization of dorsal horn neurons, which would amplify tactile input leading to allodynia. In contrast, Pitcher and Henry (2004) have argued that neuropathy induces substance $P$ synthesis in myelinated afferents that retain their peripheral terminations, and that peptide release in the dorsal horn after activation of these afferents contributes directly to tactile allodynia.

Our data strongly suggest that, although there may be de novo synthesis of substance $P$ in cell bodies of axotomized $A \beta$ afferents (Noguchi et al., 1994, 1995; Weissner et al., 2006), this does not result in significant levels of the peptide being present in, or released from, their central terminals. It is possible that some $\mathrm{A} \beta$ afferents that are damaged but not axotomized in the CCI model fail to upregulate NPY, and would therefore have been excluded from the main part of our analysis. However, because we never observed substance P immunoreactivity in boutons that contained VGLUT1 but not NPY in laminas IIi-III in this model, it is extremely unlikely that central terminals of such afferents would contain substance $\mathrm{P}$.

A possible explanation for the effect of NK1 receptor antagonists described above is that there are two distinct forms of tactile allodynia, static and dynamic, which involve different types of primary afferent (Ochoa and Yarnitsky, 1993; Field et al., 1999; Gonzalez et al., 2000). It is generally agreed that dynamic allodynia results from activation of $\mathrm{A} \beta$ afferents, whereas the static form appears to be mediated by C fibers (Ochoa and Yarnitsky, $1993)$ or capsaicin-sensitive A $\delta$ fibers (Field et al., 1999). The studies that found antiallodynic effects of NK1 receptor antagonists used von Frey hairs, and will therefore have detected static allodynia (Campbell et al., 1998; Cumberbatch et al., 1998; Cahill and Coderre, 2002). Interestingly, Gonzalez et al. (2000) reported that, whereas static allodynia after CCI was partially blocked by a NK1 receptor antagonist, dynamic allodynia was not affected. They concluded that upregulation of substance $\mathrm{P}$ in $\mathrm{A} \beta$ afferents was unlikely to have occurred in this model. Pitcher and Henry (2004) observed NK1 receptor-mediated afterdischarges in rat dorsal horn neurons in response to innocuous pressure stimuli, similar to those that generate static allodynia. The simplest explanation of these findings is that substance $\mathrm{P}$ release from $\mathrm{A} \delta$ and/or C fibers contributes to static allodynia, but that there is little or no release of substance $P$ from the $A \beta$ afferents that evoke dynamic allodynia.

\section{References}

Allen BJ, Li J, Menning PM, Rogers SD, Ghilardi J, Mantyh PW, Simone DA (1999) Primary afferent fibers that contribute to increased substance P receptor internalization in the spinal cord after injury. J Neurophysiol 81:1379-1390

Bao L, Wang HF, Cai H-J, Tong Y-G, Jin S-X, Lu Y-J, Grant G, Hökfelt T, Zhang X (2002) Peripheral axotomy induces only very limited sprouting of coarse myelinated afferents into inner lamina II of rat spinal cord. Eur J Neurosci 16:175-185.

Bennett GJ, Xie Y-K (1988) A peripheral mononeuropathy in rat that produces disorders of pain sensation like those seen in man. Pain 33:87-107.

Brown AG (1981) Organization of the spinal cord: the anatomy and physiology of identified neurones. Berlin: Springer.

Brown JL, Liu H, Maggio JE, Vigna SR, Mantyh PW, Basbaum AI (1995) Morphological characterization of substance P receptor-immunoreactive neurons in the rat spinal cord and trigeminal nucleus caudalis. J Comp Neurol 356:327-344.

Cahill CM, Coderre TJ (2002) Attenuation of hyperalgesia in a rat model of neuropathic pain after intrathecal pre- or post-treatment with a neurokinin-1 antagonist. Pain 95:277-285.

Campbell EA, Gentry CT, Patel S, Panesar MS, Walpole CS, Urban L (1998) Selective neurokinin-1 receptor antagonists are anti-hyperalgesic in a model of neuropathic pain in the guinea-pig. Neuroscience 87:527-537.

Campbell JN, Raja SN, Meyer RA, Mackinnon SE (1988) Myelinated afferents signal hyperalgesia associated with nerve injury. Pain 32:89-94.

Chaplan SR, Bach FW, Pogrel JW, Chung JM, Yaksh TL (1994) Quantitative assessment of tactile allodynia in the rat paw. J Neurosci Methods 53:55-63.

Cuello AC, Galfre G, Milstein C (1979) Detection of substance P in the central nervous system by a monoclonal antibody. Proc Natl Acad Sci USA 76:3532-3536.

Cumberbatch MJ, Carlson E, Wyatt A, Boyce S, Hill RG, Rupniak NM (1998) 
Reversal of behavioural and electrophysiological correlates of experimental peripheral neuropathy by the $\mathrm{NK}_{1}$ receptor antagonist GR205171 in rats. Neuropharmacology 37:1535-1543.

Devor M (2005) Response of nerves to injury in relation to neuropathic pain. In: Wall and Melzack's textbook of pain, Ed 5 (McMahon S, Koltzenburg M, eds), pp 905-927. Edinburgh: Churchill Livingstone.

Dixon WJ (1980) Efficient analysis of experimental observations. Annu Rev Pharmacol Toxicol 20:441-462.

Fabri M, Conti F (1990) Calcitonin gene-related peptide-positive neurons and fibers in the cat dorsal column nuclei. Neuroscience 35:167-174.

Field MJ, Bramwell S, Hughes J, Singh L (1999) Detection of static and dynamic components of mechanical allodynia in rat models of neuropathic pain: are they signalled by distinct primary sensory neurones? Pain 83:303-311.

Fukuoka T, Tokunaga A, Kondo E, Miki K, Tachibana T, Noguchi K (1998) Change in mRNAs for neuropeptides and the GABA(A) receptor in dorsal root ganglion neurons in a rat experimental neuropathic pain model. Pain 78:13-26.

Giuffrida R, Rustioni A (1992) Dorsal root ganglion neurons projecting to the dorsal column nuclei of rats. J Comp Neurol 316:206-220.

Gonzalez MI, Field MJ, Hughes J, Singh L (2000) Evaluation of selective $\mathrm{NK}_{1}$ receptor antagonist CI-1021 in animal models of inflammatory and neuropathic pain. J Pharmacol Exp Ther 294:444-450.

Gracely RH, Lynch SA, Bennett GJ (1992) Painful neuropathy: altered central processing maintained dynamically by peripheral input. Pain 51:175-194.

Hargreaves KM, Dubner R, Brown F, Flores C, Joris J (1988) A new and sensitive method for measuring thermal nociception in cutaneous hyperalgesia. Pain 32:77-88.

Hökfelt T, Zhang X, Wiesenfeld-Hallin Z (1994) Messenger plasticity in primary sensory neurons following axotomy and its functional implications. Trends Neurosci 17:22-30.

Honoré P, Rogers SD, Schwei MJ, Salak-Johnson JL, Luger NM, Sabino MC, Clohisy DR, Mantyh PW (2000) Murine models of inflammatory, neuropathic and cancer pain each generates a unique set of neurochemical changes in the spinal cord and sensory neurons. Neuroscience 98:585-598.

Hughes DI, Polgár E, Shehab SAS, Todd AJ (2004) Peripheral axotomy induces depletion of the vesicular glutamate transporter VGLUT1 in central terminals of myelinated afferent fibres in the rat spinal cord. Brain Res 1017:69-76.

Kim SH, Chung JM (1992) An experimental model for peripheral neuropathy produced by segmental spinal nerve ligation in the rat. Pain 50:355-363.

Ma W, Bisby MA (1998) Increases in calcitonin gene-related peptide immunoreactivity in the axonal fibers of the gracile nuclei of adult and aged rats after complete and partial sciatic nerve injuries. Exp Neurol 152:137-149.

Ma W, Ramer MS, Bisby MA (1999) Increased calcitonin gene-related peptide immunoreactivity in gracile nucleus after partial sciatic nerve injury: age-dependent and originating from spared sensory neurons. Exp Neurol 159:459-473.

Malcangio M, Ramer MS, Jones MG, McMahon SB (2000) Abnormal substance $P$ release from the spinal cord following injury to primary sensory neurons. Eur J Neurosci 12:397-399.

Mantyh PW, De Master E, Malhotra A, Ghilardi JR, Rogers SD, Mantyh CR, Liu H, Basbaum AI, Vigna SR, Maggio JE (1995) Receptor endocytosis and dendrite reshaping in spinal neurons after somatosensory stimulation. Science 268:1629-1632.

Marchand JE, Wurm WH, Kato T, Kream RM (1994) Altered tachykinin expression by dorsal root ganglion neurons in a rat model of neuropathic pain. Pain 58:219-231.

Miki K, Fukuoka T, Tokunaga A, Noguchi K (1998) Calcitonin gene-related peptide increase in the rat spinal dorsal horn and dorsal column nucleus following peripheral nerve injury: up-regulation in a subpopulation of primary afferent sensory neurons. Neuroscience 82:1243-1252.

Naim MM, Shehab SAS, Todd AJ (1998) Cells in laminae III and IV of the rat spinal cord which possess the neurokinin-1 receptor receive monosynaptic input from myelinated primary afferents. Eur J Neurosci 10:3012-3019.

Nakaya Y, Kaneko T, Shigemoto R, Nakanishi S, Mizuno N (1994) Immunohistochemical localization of substance P receptor in the central nervous system of the adult rat. J Comp Neurol 347:249-274.

Neumann S, Doubell TP, Leslie T, Woolf CJ (1996) Inflammatory pain hy- persensitivity mediated by phenotypic switch in myelinated primary sensory neurons. Nature 384:360-364.

Noguchi K, Dubner R, De Leon M, Senba E, Ruda MA (1994) Axotomy induces preprotachykinin gene expression in a subpopulation of dorsal root ganglion neurons. J Neurosci Res 37:596-603.

Noguchi K, Kawai Y, Fukuoka T, Senba E, Miki K (1995) Substance P induced by peripheral nerve injury in primary afferent sensory neurons and its effect on dorsal column neurons. J Neurosci 15:7633-7643.

Ochoa JL, Yarnitsky D (1993) Mechanical hyperalgesias in neuropathic pain patients: dynamic and static subtypes. Ann Neurol 33:465-472.

Pitcher GM, Henry JL (2004) Nociceptive responses to innocuous mechanical stimulation is mediated via myelinated afferents and NK-1 receptor activation in a rat model of neuropathic pain. Exp Neurol 186:173-197.

Polgár E, Hughes DI, Riddell JS, Maxwell DJ, Puskár Z, Todd AJ (2003) Selective loss of spinal GABAergic or glycinergic neurons is not necessary for development of thermal hyperalgesia in the chronic constriction injury model of neuropathic pain. Pain 104:229-239.

Polgár E, Hughes DI, Arham AZ, Todd AJ (2005) Loss of neurons from laminae I-III of the spinal dorsal horn is not required for development of tactile allodynia in the spared nerve injury model of neuropathic pain. J Neurosci 25:6658-6666.

Rivero-Melián C, Grant G (1990) Distribution of lumbar dorsal root fibers in the lower thoracic and lumbosacral spinal cord of the rat studied with choleragenoid horseradish peroxidase conjugate. J Comp Neurol 299:470-481.

Robertson B, Grant G (1985) A comparison between wheat germ agglutinin-and choleragenoid-horseradish peroxidase as anterogradely transported markers in central branches of primary sensory neurones in the rat with some observations in the cat. Neuroscience 14:895-905.

Salter MW, Henry JL (1991) Responses of functionally identified neurones in the dorsal horn of the cat spinal cord to substance P, neurokinin A and physalaemin. Neuroscience 43:601-610.

Shehab SA, Spike RC, Todd AJ (2003) Evidence against cholera toxin B subunit as a reliable tracer for sprouting of primary afferents following peripheral nerve injury. Brain Res 964:218-227.

Spike RC, Puskár Z, Andrew D, Todd AJ (2003) A quantitative and morphological study of projection neurons in lamina I of the rat lumbar spinal cord. Eur J Neurosci 18:2433-2448.

Todd AJ, Koerber HR (2005) Neuroanatomical substrates of spinal nociception. In: Wall and Melzack's textbook of pain, Ed 5 (McMahon S, Koltzenburg M, eds), pp 73-90. Edinburgh: Churchill Livingstone.

Todd AJ, Spike RC, Polgár E (1998) A quantitative study of neurons which express neurokinin 1 or somatostatin $s_{2} t_{2 \mathrm{a}}$ receptor in rat spinal dorsal horn. Neuroscience 85:459-473.

Todd AJ, McGill MM, Shehab SAS (2000) Neurokinin 1 receptor expression by neurons in laminae I, III and IV of the rat spinal dorsal horn that project to the brainstem. Eur J Neurosci 12:689-700.

Todd AJ, Hughes DI, Polgár E, Nagy GG, Mackie M, Ottersen O-P, Maxwell DJ (2003) The expression of vesicular glutamate transporters VGLUT1 and VGLUT2 in neurochemically defined axonal populations in the rat spinal cord with emphasis on the dorsal horn. Eur J Neurosci 17:13-27.

Tong Y-G, Wang HF, Ju G, Grant G, Hökfelt T, Zhang X (1999) Increased uptake and transport of cholera toxin b-subunit in dorsal root ganglion neurons after peripheral axotomy: possible implications for sensory sprouting. J Comp Neurol 404:143-158.

Torebjörk HE, Vallbo AB, Ochoa JL (1987) Intraneural microstimulation in man. Its relation to specificity of tactile sensations. Brain 110:1509-1529.

Wakisaka S, Kajander KC, Bennett GJ (1991) Increased neuropeptide Y (NPY)-like immunoreactivity in rat sensory neurons following peripheral axotomy. Neurosci Lett 124:200-203.

Wakisaka S, Kajander KC, Bennett GJ (1992) Effects of peripheral nerve injuries on the levels of neuropeptide Y-like immunoreactivity in rat primary afferent neurons. Brain Res 598:349-352.

Weissner W, Winterson BJ, Stuart-Tilley A, Devor M, Bove GM (2006) Time course of substance P expression in dorsal root ganglia following complete spinal nerve transection. J Comp Neurol 497:78-87.

Willis WD, Coggeshall RE (2004) Sensory mechanisms of the spinal cord, Vol 2. New York: Kluwer Academic.

Zhang X, Meister B, Elde R, Verge VM, Hökfelt T (1993) Large calibre primary afferent neurons projecting to the gracile nucleus express neuropeptide Y after sciatic nerve lesions: an immunohistochemical and in situ hybridization study in rats. Eur J Neurosci 5:1510-1519. 